\title{
Transformações, isometrias e grupos - do ensino básico ao ensino superior
}

\author{
Márcia Cristina Lemos Guimarães* \\ Instituto de Matemática, Estatística e Computação Científica, UNICAMP \\ 13083-859, Campinas, SP \\ E-mail: mclgui@hotmail.com \\ Claudina Izepe Rodrigues \\ Universidade Estadual de Campinas - Departamento de Matemática \\ 13083-859, Campinas, SP \\ E-mail: claudina@ime.unicamp.br
}

\begin{abstract}
RESUMO
É de grande relevância o ensino das transformações geométricas, tanto no ensino básico como no ensino superior, pois são ferramentas muito úteis em demonstrações, para resolver problemas de geometria, na introdução da ideia de grupos e no raciocínio matemático em geral.

Uma transformação geométrica no plano é uma correspondência biunívoca do conjunto dos pontos do plano nele mesmo. Em particular, se $F$ é uma figura no plano, a imagem de $F$ pela transformação $T$ é o conjunto $\mathrm{F}^{\prime}$ dos pontos imagens de $F$, denotado por $F^{\prime}=T(F)$. Dentre as transformações geométricas no plano temos as isometrias e a homotetia, que são princípios básicos para os conceitos de congruência e de semelhança, respectivamente. Vamos direcionar nosso estudo para as isometrias no plano.

Isometria é uma transformação geométrica que preserva a distância entre pontos. São isometrias: translações, rotações, reflexões e reflexões deslizantes. O conjunto das isometrias possui uma estrutura algébrica de grupo com a operação composição.

Grupos de simetria de uma figura: considerando $\mathrm{F}$ o conjunto de pontos de uma figura contida no plano $\mathrm{P}$, o grupo de simetrias de $\mathrm{F}$ é o conjunto de todas as transformações no plano que deixam $\mathrm{F}$ invariante, ou seja, o conjunto imagem de $\mathrm{F}$ é o próprio $\mathrm{F}$. O processo de determinar o grupo de simetria pode ser exaustivo. $\mathrm{O}$ uso do algoritmo I para determinar o grupo de simetrias de uma figura limitada pode tornar esse trabalho mais simplificado. No algoritmo, $C_{n}$ denota o grupo cíclico gerado por uma rotação de ordem $n$ e $D_{n}$ denota o grupo diedral de ordem $2 n$.
\end{abstract}

Algoritmo I - Grupo de simetria de figuras limitadas

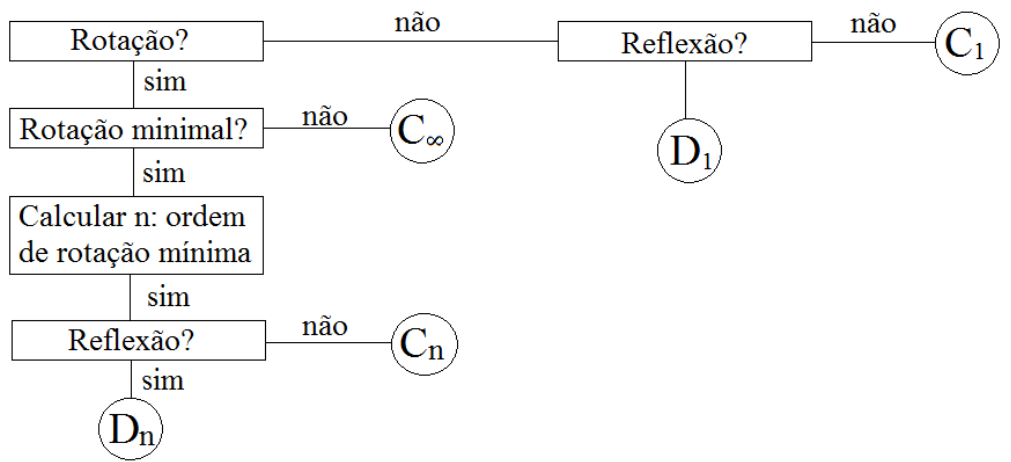

Grupos de frisos: Um grupo de isometrias que deixam invariante uma reta c e cujas translações formam um grupo cíclico infinito é um Grupo de Frisos com centro c. Existem 7 desses grupos.

A proposta deste trabalho para desenvolver os temas abordados acima é usar atividades envolvendo simetria tendo em vista a familiarização do aluno com a ideia de transformações e de grupos. 


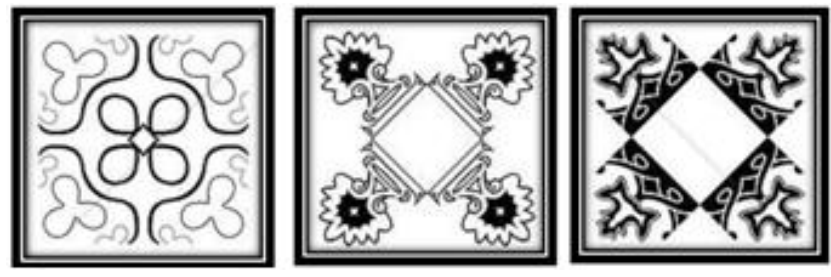

Figura 1

Apenas observando a figura 1 conseguimos identificar suas simetrias: 4 reflexões e 4 rotações. Denotemos o conjunto das simetrias da figura como $S=\left\{R_{1}, R_{2}, R_{3}, R_{4}, 90^{\circ}, 180^{\circ}, 270^{\circ}\right.$, $360^{\circ}$ \}. O uso de recursos computacionais permite uma melhor visualização de tais simetrias, bem como fazer composições com as mesmas. A composição de uma rotação de $90^{\circ} \mathrm{com}$ uma rotação de $180^{\circ}$ produz uma rotação de $270^{\circ}$ que pertence ao conjunto $\mathrm{S}$. Podemos fazer outras composições como, duas reflexões em torno do mesmo eixo ou uma rotação de $-90^{\circ}$, e verificar que também pertencem ao conjunto $S$. Escolhendo três elementos do conjunto $S$, por exemplo, $R_{2}, R_{4}$ e $90^{\circ}$, e operando-os da seguinte forma: $\left[\left(R_{2}\right.\right.$ o $\left.R_{4}\right)$ o $\left.90^{\circ}\right]$ e $\left[R_{2}\right.$ o $\left(R_{4}\right.$ o $\left.\left.90^{\circ}\right)\right]$ podemos verificar que as duas formas de composição deixam a figura na mesma posição. Observe que, ao desenvolver passo a passo esta atividade estamos introduzindo a ideia de grupo sem necessariamente dar a definição dessa estrutura algébrica. Usando a linguagem adequada para cada faixa etária, podemos aplicá-la tanto no ensino básico como no ensino superior.

$\mathrm{O}$ algoritmo I pode ser aplicado para identificar o grupo de simetria de uma figura limitada, pois simplifica o trabalho.

Para iniciar a ideia de grupos de frisos, podemos criar faixas ornamentais usando os recursos do geogebra abordando os 7 tipos de frisos. Como exemplo, utilizando reflexão deslizante produzimos a figura 2 .

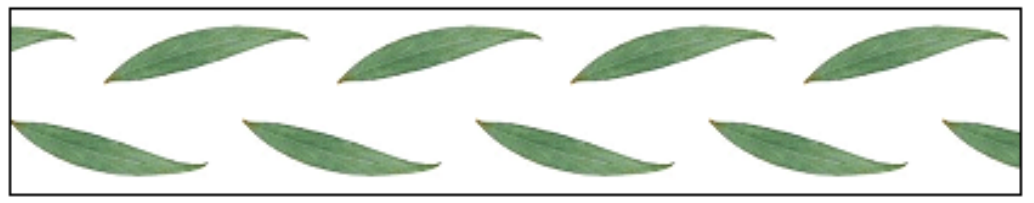

Figura 2

Esperamos que ao final deste trabalho o aluno tenha assimilado a ideia de transformações e de grupos. Tais conceitos são muito úteis na resolução de diversos problemas.

Palavras-chave: Transformações, isometrias, ensino, geometria e geogebra.

\section{Referências}

[1] Hernstein, I. N, Tópicos de Álgebra, Polígono S. A., 1970.

[2] Lima. E. L, Isometrias, Coleção do Professor de Matemática, Sociedade Brasileira de Matemática. Rio de Janeiro, 1996.

[3] Martin, G. E. Transformation Geometry. An Introduction to Symmetry. Springer-Verlag, New York, 1982.

[4] Rose, Bruce I. e Stafford, Robert D., An Elementary Course in Mathematical Symmetry, Mathematical Association of America, Vol. 88, No. 1 (Jan., 1981), pp. 59-64.

[5] Schattschneider. Doris, The Plane Symmetry Groups: Their Recognition and Notation, Mathematical Association of America, 85 (6), pp. 439-450, 1978.

[6] Veloso. Eduardo. Geometria-Temas Actuais, Instituto de Inovação Educacional, 2000.

[7] Yaglom.I.M, Geometric Transformations I, The Mathematical Association of America, 1962. 